\title{
Pasture Management And Winter Feed
}

One of the main objectives of pasture management is to meet the annual feed demand of stock by manipulating the annual feed supply from pasture. This challenge is probably greatest for high country runholders because long cold winters and often dry summers severely disrupt the continuity of pasture growth and create a mismatch between supply and demand. Within each high country run there is generally a diverse range of landscapes environments whose integration with planning, and an appropriate choice of pasture species, and selective management, can help overcome this mismatch.

Pasture growth is very tightly controlled by climate. In that sense animals may be more flexible than plants in that, because of their fat reserves, they can tolerate some management variation in feed intake and body weight. For example, winter hay feeding can be reduced by building up extra body weight in late autumn/early winter on standing alsike before it loses its feeding value by frosting, instead of trying to maintain or build acceptable body weights in winter with extra hay.

Good management in pastoral farming is working out a compromise between the conflicting requirements of animals and pastures.

The ideal management from the point of view of the pasture would be to allow it to grow to approximately three quarters of its maximum height or bulk, then to graze or cut it within a very short time (hours rather than weeks), and then allow it to regrow to the same level again before repeating the cycle. While impractical in most grazing systems, it illustrates the three desirable principles of pasture management which should be aimed for:

Very quick removal

\section{Minimal treading}

Uninterrupted regrowth back to near maximum bulk or height.

In contrast, the ideal management from an animal viewpoint would be a constant and adequate supply of quality feed.

The important principle in management is not that pastures are grazed in a regular sequence, but rather that they are grazed intensively for a short period and then allowed to regrow uninterrupted until adequate bulk is achieved (e.g. 10-20 cm high). These management principles encourage nonselective grazing and good utilisation, and favour the regrowth patterns of desired pasture species.. Note' that the period required for regrowth may differ widely between pastures on different sites, and between' pastures grazed at different times of the year.

\section{Utilisation}

Pasture utilisation refers to the consumption of pasture by the grazing animal. All pasture not consumed must eventually die and decay, and therefore, while not directly contributing to animal production in the short term, will add to the soil organic matter and fertility in the longer term. The more consumed relative to that grown, the greater the efficiency of utilisation.

Generally the aim should be to achieve $60-70 \%$ utilisation of available inter-tussock herbage in no more than 10 days. On more extreme dry sites, particularly where ground cover conservation has priority, the utilisation should be less, with the ruleof-thumb being take half and leave half. This allows the maintenance of a greater root mass and reserves for regrowth, and protects the soil surface from wind erosion.

Special purpose pastures convey the desirable concept of each area or paddock being managed to fulfil feed requirements at a certain stage of each year. The runholder should aim for the integration of a sequence of special purpose paddocks rather than rotational grazing. On better sites, the same paddock could fulfil feed requirements many times during the year, thus approaching the concept of rotational grazing.

In addition to providing the immediate feed requirements for animals, and growth requirements for pastures, successful grazing management involves continual forward planning to help balance the known stock feed demand with the expected feed supply. Subdivision provides the means to control utilisation, allowing a bank of feed to build up ahead of stock when pasture growth is good (e.g. spring and autumn). This feed bank can then be carried over and effectively used during periods of feed deficit.

It may take up to 10 years to realise the full potential from topdressing, intensive grazing and adequate spelling for regrowth. However, with such management, up to an I-fold increase in carrying capacity over that in the native state can be achieved. 
Pasture utilisation is a stock numbers game. If stocking rate is increased, so is efficiency of utilisation - but herbage allowance will decrease and so eventually will individual animal performance. The ideal stocking rate obviously depends on farmer objectives, but grazing research on oversown tussock country has shown that optimum liveweights per hectare are achieved when pasture utilisation per grazing is about $60-70 \%$. For optimum wool production per hectare, even higher levels of utilisation are required. The greater the stocking rate the greater the efficiency of utilisation, but the more difficult it is to match annual feed demand to annual feed supply.

Subdivision fencing provides the essential key to control utilisation. Increased subdivision allows even and non-selective grazing, gives increased flexibility when carrying pasture from the periods of plenty to periods of deficit, and promotes more efficient re-cycling and spread of nutrients.

\section{Winter Feed}

To balance the highly seasonal nature of pasture growth with the more constant feed requirements of stock, feed has to be transferred from one period of a year to another, principally between spring and the following winter. The greater the overall stocking rate relative to the overall feed supply, the more difficult it is to overcome any imbalance.

Gains in stock liveweight should not be expected during winter. The best that can be hoped for is maintaining or having only slight losses in liveweights. Weight losses during the winter are generally compensated for by greater weight gains during the following spring. The exception to this is the breeding stock. High weights are advantageous for flushing during the autumn. There is some evidence that low weights during early pregnancy (early winter) are not detrimental, but the evidence is unanimous that feeding must be more than adequate during late pregnancy, particularly in the last few weeks.

Special winter feed paddocks will generally be used in conjunction with other undeveloped or developed paddocks. Stock take some time to adapt to new types of feed because of changes in the rumen micro-organisms. Hence, different feeds should be introduced slowly over several weeks prior to their real need.

\section{Conserved Feed}

One option is to conserve feed, usually as hay. The common hay mixtures are based on combinations of red clover, alsike, cocksfoot or timothy in the mid to high rainfall area and luceme in the drier zone.
There is also a tendency to prefer alsike rather than red clover in the highest rainfall zone, both for its better performance at moderate levels of soil fertility, and its hollow stem which cures more rapidly than the solid stem of red clover.

Under dryland conditions, only one hay cut can be assured in many areas, with perhaps a second in good years. With irrigation, two or more cuts can be expected, increasing the reliability of winter feed. This may justify irrigation in many of the moderate and lower rainfall areas where there are limited winter feed options.

Hay is the usual form of conserved feed, principally because of its straightforward preparation (subject to the normal vagaries of weather) and its flexibility when feeding out during winter. It is generally only of maintenance feed value, and in most situations winter liveweight gains of stock cannot be expected. The allowance rate is commonly $0.8 \mathrm{~kg} / \mathrm{sheep} /$ day, though for ewes in lamb it should be increased to $1 \mathrm{~kg} / \mathrm{ewe} /$ day in early winter and $1.5 \mathrm{~kg} /$ ewe/day in late winter.

Good quality silage can be made more consistently than good quality hay because silage making does not need long periods of fine weather. Unlike hay, silage retains its quality for many years if properly made. Silage requires more machinery though, particularly when feeding out. Haylage, or wilted silage, is a possible compromise. The pasture species recommended for hay making are also ideal for silage and haylage, but should be cut at an earlier stage of growth to ensure the best quality.

Hay or silage paddocks are good examples of special purpose pastures, having specific fencing, fertiliser, species and often irrigation requirements. They are the most expensive of the winter feed options but have the advantage that the reserves available are known well before the winter period.

To maintain density of hay paddocks, a hay cut may have to be replaced periodically with grazing to clean out the bottom of stands and promote tillering of grasses.

To compensate for nutrient transfer when conserved feed is fed out on areas other than those on which it was made, fertiliser application rates on hay paddocks will need to be higher than elsewhere. Also, when the feed out areas are different, care is needed to ensure that the resident vegetation does not become overgrazed because of the higher stocking rates.

\section{Autumn Saved Pasture}

An attractive and now widespread alternative to hay or silage making is to close up improved hill blocks 
at some stage during the growing season to provide winter grazing. Success depends largely on the ability to maintain pasture with reasonable bulk and acceptability into the winter. Pasture species differ in this respect. For instance, browntop and haresfoot clover are virtually unacceptable to stock once they have developed seed heads, while timothy, perennial bromes, and most legumes are quite acceptable even when rank. Legume quantity and quality deteriorates rapidly when subjected to frosting. Introduced grasses are clearly a desirable component of autumn saved pastures.

Pasture growth in the high country is negligible during winter, so management of autumn saved pasture becomes a feed budgeting exercise.

Autumn saved pastures and their use on hill blocks take two forms. Blocks at the highest altitudes, or legume dominant pastures, are used in late autumn or early winter. The objective is to eat the herbage before it loses feed quality by frosting, or disappears under snow, and to put on animal body weight to tolerate lower feeding levels later in the winter.

Alsike and red clover are important in this approach. The other approach is to exploit the greater frost tolerance of grasses as direct standing feed in mid and late winter. Grass dominant blocks, particularly those on sunny faces, can be used in this manner.

The closing of those sown grass/legume pastures for winter feed may be as early as the previous November. However, close grazing, then closing in December greatly reduces the less acceptable species like browntop. Cocksfoot is the most useful sown grass. There is a trade-off between bulk and feeding quality in such autumn saved pasture.

An example of all-grass wintering on hill country would be ten saved blocks to ration out over June, July and August, with stock shifts every 5-15 days depending on size of block, amount of feed, aspect, and other factors which might determine the duration of grazing.

Most high country all-grass wintering is achieved on large sunny hill blocks. It is possible to intensively break feed special purpose pasture grown on the flat, throughout the winter. Areas may be used strategically in late winter, allowing spelling of the lower sunny faces, which provide early spring feed.
Grasses for such pastures ranked for suitability according to a combination of both autumn productivity and winter quality are as follows: cocksfoot, ryegrass, tall fescue and bromes.

Autumn regrowth from hay paddocks can be used in the same manner. These special purpose pastures could be grass, using nitrogen fertiliser at 150 $300 \mathrm{kgN} / \mathrm{ha}$ in split applications. One method used irrigated tall fescue, nitrogen fertiliser, with 1-2 hay cuts, allowing autumn regrowth, and winter feeding out in that area with sheep receiving standing forage and hay.

\section{Annual Crops}

Greenfeed crops produce well on select areas of high fertility, but must be sown earlier than they would be on down country. The bulbs of swedes and turnips, with their high water content, can freeze, leaving only their tops edible. Rapes and kales do not suffer the same disadvantage.

Ryecom and, to a lesser extent, oats and barley are the main greenfeed cereals, indicating their adaptation to both cooler temperatures and moderate soil fertility. Some varieties of triticale and wheat are also suitable as greenfeed crops but have less regrowth following grazing and generally require higher soil fertility than ryecom, oats, or barley.

Annual greenfeed ryegrasses are generally not suitable in the high country because they need more fertile soil and early sowing to express their growth potential. However, there are occasionally very good crops of these species.

All annual crops require sites of high soil fertility. The exception may be the common practice of taking an oat crop following initial cultivation of tussock grasslands using the consequent mineralisation of soil organic matter. It may be economically justifiable in the short term, but it must be followed by fertiliser input for sustainability.

\section{Supplements}

Supplements or concentrates in the form of grain (ryecom, wheat, oats, barley), molasses or bone meal are used on some developed runs during times of critical feed shortage. 